\title{
Correction to: On the Logical Philosophy of Assertive Graphs
}

\author{
Daniele Chiffi ${ }^{1}$ - Ahti-Veikko Pietarinen ${ }^{2,3,4}$
}

Published online: 16 May 2020

(c) Springer Nature B.V. 2020

\section{Correction to: Journal of Logic, Language and Information https://doi.org/10.1007/s10849-020-09315-6}

This erratum is to correct in the paper of Daniele Chiffi and Ahti-Veikko Pietarinen, On the Logical Philosophy of Assertive Graphs, Journal of Logic, Language and Information, the publisher's error of inscribing the following graphs in Section 2.3.2

- The Rule of Antecedent Separation/Antecedent Merging (As/Am)

- Consequent Merging/Consequent Separation (Cm/Cs)

- Rules of Disjunct Contradiction (DC)

- Cornering Rules (CR/UCR)

on the same line that omitted the line skip in the original proof of the manuscript.

Publisher's Note Springer Nature remains neutral with regard to jurisdictional claims in published maps and institutional affiliations.

The original article can be found online at https://doi.org/10.1007/s10849-020-09315-6.

\footnotetext{
Ahti-Veikko Pietarinen ahti.pietarinen@gmail.com

Daniele Chiffi

chiffidaniele@gmail.com

1 Politecnico di Milano, Milan, Italy

2 Nazarbayev University, Nur-Sultan, Kazakhstan

3 HSE University, Moscow, Russian Federation

4 Tallinn University of Technology, Tallinn, Estonia
} 